\title{
Crystal structure of theophylline-7-acetic acid, $\mathrm{C}_{9} \mathrm{H}_{10} \mathrm{~N}_{4} \mathrm{O}_{4}$
}

\author{
L.-J. Zhang, ${ }^{\mathrm{I}}$ M.-C. Liu',II, J.-C. Ding ${ }^{\mathrm{II}}$ and H.-Y. Wu ${ }^{\mathrm{II}}$ \\ I Wenzhou University, Elementary Educational College, Wenzhou 325027, P. R. China \\ II Wenzhou University, School of Chemistry and Material Science, Wenzhou 325027, P. R. China
}

Received January 7, 2006, accepted and available on-line February 1, 2006; CCDC no. 1267/1716
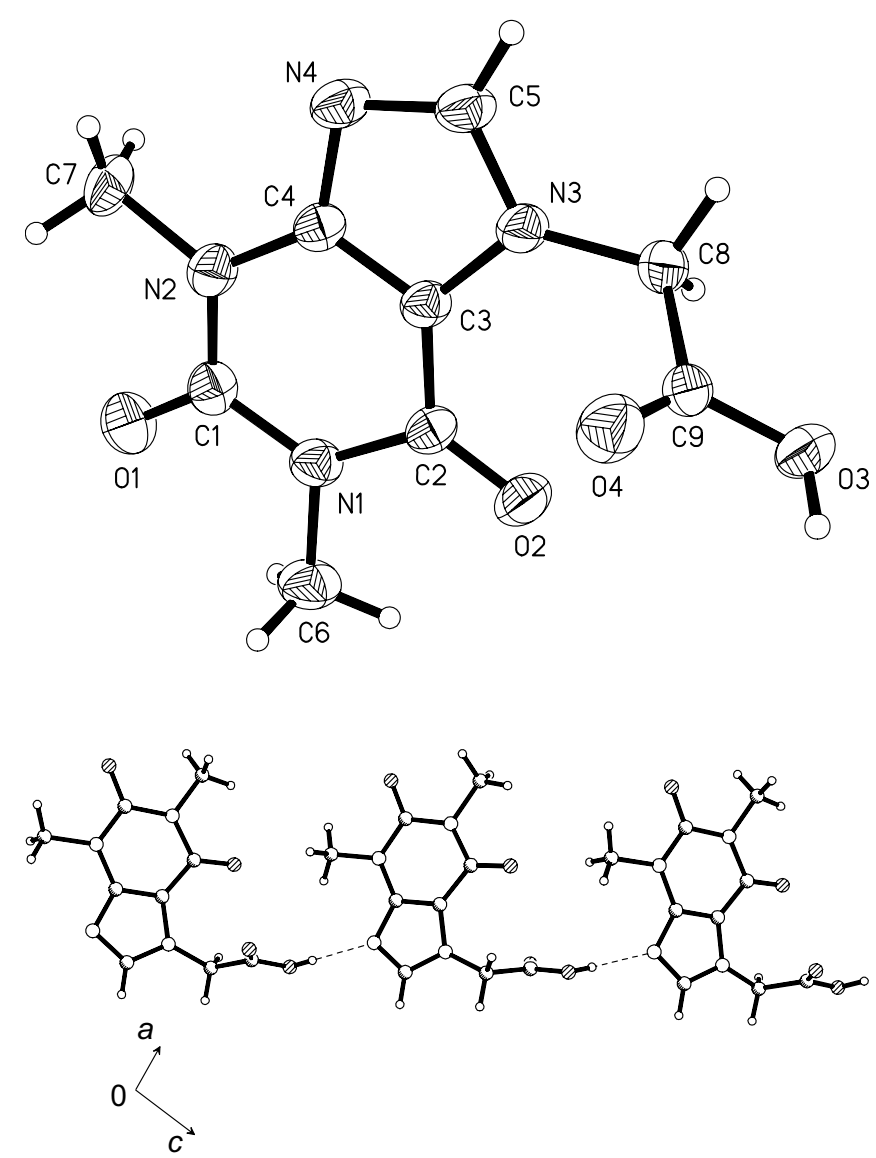

\section{Abstract}

$\mathrm{C}_{9} \mathrm{H}_{10} \mathrm{~N}_{4} \mathrm{O}_{4}$, monoclinic, $P 12{ }_{1} / n 1$ (no. 14),

$a=9.542(1) \AA, b=7.2415(9) \AA, c=14.446(2) \AA$,

$\beta=98.657(2)^{\circ}, V=986.8 \AA^{3}, Z=4, R_{\mathrm{gt}}(F)=0.053$, $w R_{\mathrm{ref}}\left(F^{2}\right)=0.138, T=298 \mathrm{~K}$.

\section{Source of material}

The title compound was prepared by the hydrocarbylation of theophylline $(1.8 \mathrm{~g}, 10 \mathrm{mmol})$ and bromoacetic acid $(9 \mathrm{mmol}$, $1.25 \mathrm{~g}$ ) in the presence of tetrabutylammonium bromide catalyst $(0.3 \mathrm{~g})$. The reaction was carried out in a $630 \mathrm{~W}$ microwave oven for $1 \mathrm{~min}$. Single crystals were obtained by recrystallization from ethanol solution.

\section{Discussion}

Xanthine derivatives are the naturally occurring drugs which find use as central nervous system stimulants. Caffeine, theophylline and theobromine are methyl derivatives of xanthine. Chemically theophylline is 1,3-dimethyl xanthine; caffeine - 1,3,7-trimethyl xanthine; theobromine - 3,7-dimethyl xanthine. Recently, more and more attention has been paid on the three alkaloid owing to their significant physiological effects, such as strong diuresis, cardiac stimulation as well as arterial dilation and are useful products in the food and pharmaceutical industries [1-3]. This has stimulated our interest in its derivatives and a derivative of theobromine, ethyl theobromineacetate [4]. To extend this research, we have synthesized a derivative of theophylline, theophylline-7-yl acetic acid, and determined its crystal structure.

The acetic part $(\mathrm{C} 8 / \mathrm{C} 9 / \mathrm{O} 3 / \mathrm{O} 4)$ and the theophylline heterocycle $(\mathrm{C} 1 / \mathrm{C} 2 / \mathrm{C} 3 / \mathrm{C} 4 / \mathrm{C} 5 / \mathrm{N} 1 / \mathrm{N} 2 / \mathrm{N} 3 / \mathrm{N} 4)$ are each almost planar (figure, top). The dihedral angle between the above planes is $75.09(8)^{\circ}$. Moreover, the $\mathrm{C}-\mathrm{N}$ bond lengths in the theophylline heterocycle range from $1.327(3) \AA$ to $1.408(3) \AA$, which are shorter than a C-N single bond length (ca $1.443 \AA$ [5], but longer than a typical $\mathrm{C}=\mathrm{N}$ bond length (ca $1.269 \AA$ ) , indicating the electron delocalization. One distinct hydrogen bond occurs in the crystal structure: adjacent molecules are linked by the intermolecular $\mathrm{O} 3-\mathrm{H} 3 \cdots \mathrm{N} 4(x+1 / 2,-y+1 / 2, z+1 / 2)$ bond leading to chains along [101] direction (figure, bottom).

Table 1. Data collection and handling.

$\begin{array}{ll}\text { Crystal: } & \begin{array}{l}\text { colorless block, } \\ \text { size } 0.09 \times 0.15 \times 0.16 \mathrm{~mm}\end{array} \\ \text { Wavelength: } & \text { Mo } K_{\alpha} \text { radiation }(0.71073 \AA) \\ \mu: & 1.29 \mathrm{~cm}^{-1} \\ \text { Diffractometer, scan mode: } & \text { Bruker SMART APEX CCD, } \varphi / \omega \\ 2 \theta_{\text {max }}: & 50.54^{\circ} \\ N(h k l)_{\text {measured }}, N(h k l)_{\text {unique }}: & 5068,1788 \\ \text { Criterion for } I_{\text {obs }}, N(h k l)_{\mathrm{gt}}: & I_{\mathrm{obs}}>2 \sigma\left(I_{\mathrm{obs}}\right), 1458 \\ N(\text { param })_{\text {refined }}: & 157 \\ \text { Programs: } & \text { SHELXS-97 [6], SHELXL-97 [7] }\end{array}$

Table 2. Atomic coordinates and displacement parameters (in $\AA^{2}$ ).

\begin{tabular}{llllll}
\hline Atom & Site & $x$ & $y$ & $z$ & $U_{\text {iso }}$ \\
\hline $\mathrm{H}(3)$ & $4 e$ & 1.0578 & 0.3555 & 0.4174 & 0.057 \\
$\mathrm{H}(5)$ & $4 e$ & 0.6155 & 0.2763 & 0.1198 & 0.040 \\
$\mathrm{H}(6 \mathrm{~A})$ & $4 e$ & 1.3392 & 0.1907 & 0.0482 & 0.064 \\
$\mathrm{H}(6 \mathrm{~B})$ & $4 e$ & 1.3268 & 0.3836 & 0.0956 & 0.064 \\
$\mathrm{H}(6 \mathrm{C})$ & $4 e$ & 1.3191 & 0.3698 & -0.0133 & 0.064 \\
$\mathrm{H}(7 \mathrm{~A})$ & $4 e$ & 0.8122 & 0.2472 & -0.1885 & 0.061 \\
$\mathrm{H}(7 \mathrm{~B})$ & $4 e$ & 0.7750 & 0.0570 & -0.1464 & 0.061 \\
$\mathrm{H}(7 \mathrm{C})$ & $4 e$ & 0.9140 & 0.0780 & -0.1911 & 0.061 \\
$\mathrm{H}(8 \mathrm{~A})$ & $4 e$ & 0.7543 & 0.4272 & 0.2624 & 0.038 \\
$\mathrm{H}(8 \mathrm{~B})$ & $4 e$ & 0.8849 & 0.5358 & 0.2360 & 0.038 \\
& & & & & \\
\hline
\end{tabular}

\footnotetext{
* Correspondence author (e-mail: mcl@wznc.zj.cn)
} 
Table 3. Atomic coordinates and displacement parameters (in $\AA^{2}$ ).

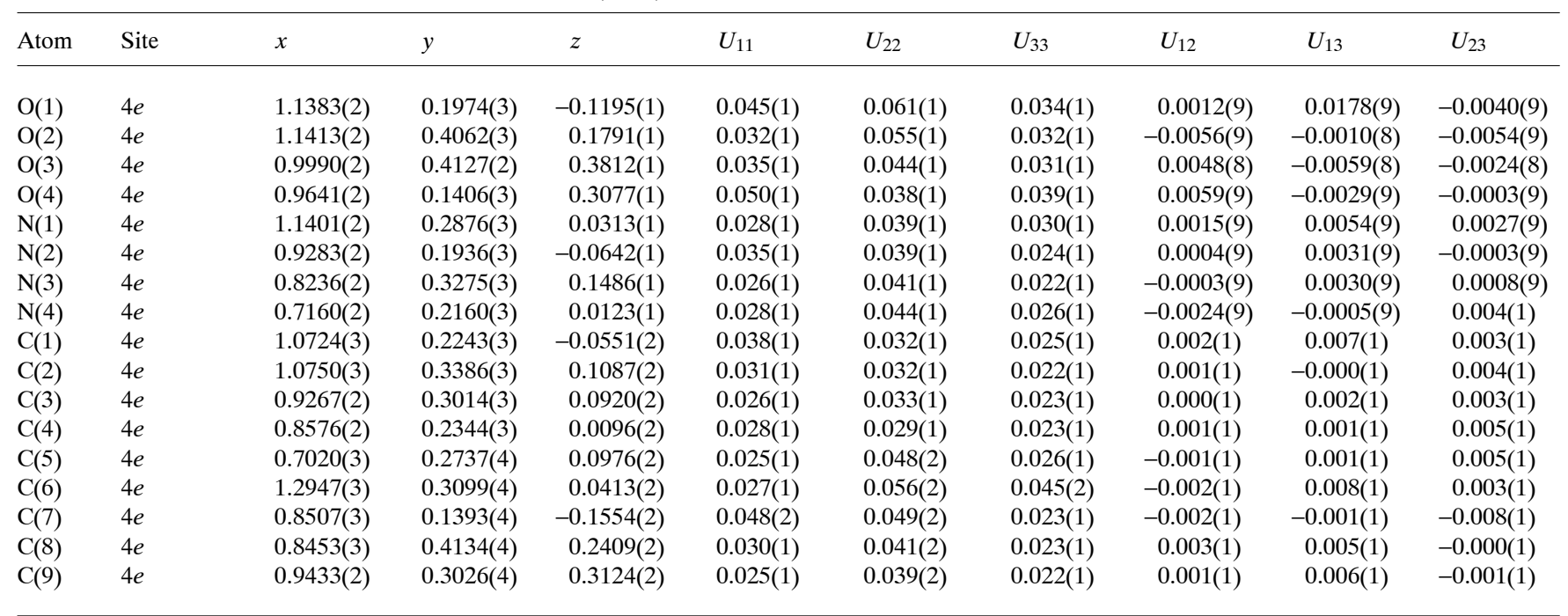

Acknowledgments. We acknowledge financial support by the Wenzhou Technology Project Foundation of China (grant nos. G2004053 and S2004A004) and the National Natural Science Foundation of China (grant no. 20571057).

\section{References}

1. Gunasekaran, S.; Sankari, G.; Ponnusamy, S.: Vibrational spectral investigation on xanthine and its derivatives - theophylline, caffeine and theobromine. Spectrochim. Acta A61 (2005) 117-127.

2. Lo, Y. C.; Tsou, H. H.; Lin, R. J.; Wu, D. C.; Wu, B. N.; Lin, Y. T.; Chen, I. J.: Endothelium-dependent and -independent vasorelaxation by a theophylline derivative MCPT: Roles of cyclic nucleotides, potassium channel opening and phosphodiesterase inhibition. Life Sci. 76 (2005) 931-944.

3. Campillo, N.; Garcia, C.; Goya, P.; Alkorta, I.; Páez, J. A.: Novel Bronchodilators: Synthesis, Transamination Reactions, and Pharmacology of a Series of Pyrazino[2,3-c][1,2,6]thiadiazine 2,2-Dioxides. J. Med. Chem. 43 (2000) 4219-4227.
4. Ding, J. C.; Feng, W.; Wu, H. Y.; Pan, Z. K.: Ethyl (3,7-dimethyl-2,6-dioxo-2,3,6,7-tetrahydro-purin-1-yl)acetate. Acta Crystallogr. E60 (2004) o1518-o1519.

5. Jin, Z. M.; Li, L.; Li, M. C.; Hu, M. L.; Shen, L.: Diethyl 3,8-dimethyl-4,7diazadeca-2,8-dienedioate. Acta Crystallogr. C60 (2004) o642-o643.

6. Sheldrick, G. M.: SHELXS-97. Program for the Solution of Crystal Structures. University of Göttingen, Germany 1997.

7. Sheldrick, G. M.: SHELXL-97. Program for the Refinement of Crystal Structures. University of Göttingen, Germany 1997. 